Send your letters to the editor, British Dental Journal, 64 Wimpole Street, London W1G 8YS or by email tobdj@bda.org

Priority will be given to letters less than 500 words long. Letters should be typed. Authors must sign the letter, which may be edited for reasons of space

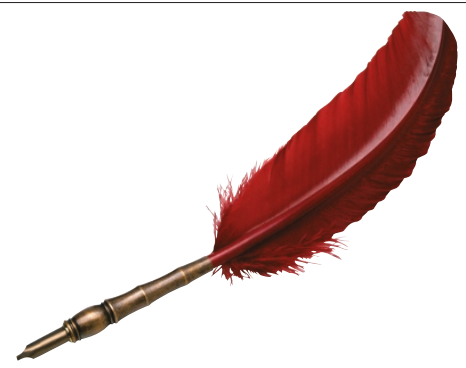

\section{External defibrillators}

Sir, I read with great interest the paper on external automated defibrillators (BDJ 2005, 198:209). Although I thoroughly agreed with it, I was concerned about the picture showing the Access AED defibrillator. This defibrillator was being sold by various UK dental distributors for over a year until last November. It even had a favourable review by Dental Practice magazine. It was produced by an American company which has since gone into voluntary liquidation as it was having financial difficulties for over a year. The company had several impending law suits against it due to the faulty algorithm in the defibrillator such that it may not have delivered an appropriate shock when needed.

This information was apparently common knowledge in the healthcare sector, yet the UK distributors continued to sell it to many practitioners. I bought one of these for my practice on the advice of a well known dental supply company in September 2004. I had long thought that basic CPR was not enough for cardiac emergencies in general practice and knew the machines were much easier to use since the advent of automatic technology.

I was surprised that two months later the machines were being recalled and the company had gone into receivership. Therefore I was concerned that the article shows the Access AED and by inference could be seen to endorse the product.

I would not want fellow practitioners to assume that this is a worthwhile machine. I have returned mine and replaced it with the Phillips defibrillator, which I am now told by the local resuscitation team is the brand leader and is also cheaper!

\section{R. F. Colin}

\section{Hertfordshire}

Sir, I read with great interest the article on automatic external defibrillators (AEDs) (BDJ 2005, 198:209). The authors refer to the International Guidelines 2000 for Cardiopulmonary Resuscitation and Emergency Cardiac Care (ECC) which emphasise the importance of early defibrillation in cases of cardiac arrest.

Indeed, such is the evidence for early defibrillation that the ECC Guidelines 2000 now stress the need to contact the emergency services immediately; and to bring any nearby AED having established unresponsiveness in a collapsed subject such that a defibrillator is brought to the scene as quickly as possible.

This should be instigated prior to checking to see if the patient is breathing or has a pulse even if you are on your own which would necessitate you to leave the patient to carry this out. All the more reason for the authors to suggest reconsideration of our profession's guidelines to include training in the use of AEDs.

\section{P. O'Leary}

Ireland

doi: 10.1038/sj.bdj.4812443

\section{Editor's note}

We would like to make clear a situation that has arisen as a result of a letter published in the $B D J$ (Professional indemnity $B D J 2005,198: 187)$. There was a suggestion in the letter that the Legal Advisor of the $B D J, \mathrm{Mr}$

Christopher Morris, had seemed 'oblivious' to a clarification on the matter of indemnity contained in an announcement by the Department of Health.

It is now apparent that the clarification referred to had not been a specific announcement and thus there was no specific reason why the Legal Advisor might have been aware of it. Consequently we would like to apologise to Mr Morris for the publication of this implication and for any professional or personal embarrassment that this may have caused.

\section{S. Hancocks}

Editor-in-Chief

doi: 10.1038/sj.bdj.4812450 